\title{
Wind Turbine using Doubly-Fed Induc- tion Generator Protection during Fault
}

\author{
KONE Ibrahima ${ }^{1}$ Chengyong $\mathrm{Zhao}^{2}$ \\ ${ }^{1}$ School of Electrical and Electronics Engineering North China Electric Power \\ University Beijing, CHINA \\ ibrimfr@yahoo.fr \\ ${ }^{2}$ Member, IEEE, School of Electrical and Electronics Engineering North China Electric \\ Power University Beijing, CHINA \\ chengyongzhao@ncepu.edu.cn
}

\begin{abstract}
In this work the user wind turbine component is created using FORTRAN and implemented in PSCAD. The fault current limiter (FCL) is associated with braking resistor to reduce fault current and DC link voltage. The comparative simulation is done with and without the protection devices under the three phase and the single phase faults. The converter remains connected and continue to control the wind turbine. Finally, it is proved that the use of fault current limiter with the active crowbar can protect the wind turbine during fault or low voltage, thus ensuring it uninterruptible operation.
\end{abstract}

Keywords: DFIG, FCL, LVRT, active crowbar

This work was supported by National Science Foundation of China (No. 51177042), Key Project of the National Twelfth-Five Research Program of China (2010BAA01B01)

\section{Introduction}

Nowadays the major party of installed wind turbines uses variable speeds, which increases the capacity of the integration to the network. The doubly fed induction generator (DFIG) is the most popular.
Unlike the Full Rated Converter (FRT), in DFIG wind turbine only a portion of the energy passes through the converter. Thus, the power converter is designed to the third of the wind turbine total power. Wind turbine is designed in such a way that, the stator windings are directly connected to the network, while the rotor circuit is connected via the power converter. In much research work, the DFIG is modeled as a current source $[1,2,3]$. In their research, the current control strategy is generally used to control the rotor side converter $[4,5]$.

In this work, the DFIG is modeled as a voltage source behind impedance [6]. Here, the rotor side converter is used to control the wind-turbine terminal voltage, active power, the internal voltage magnitude and angle while the grid side converter maintains the DC bus voltage constant.

During the fault condition, the wind turbine is unable to send the power to the grid. If the wind speed is sufficiently high, the turbine continues to generate power, causing the rotor current to rise and then the DC link voltage increase. Traditionally, wind turbine generators were tripped off once the voltage at their terminals reduced to a specified level. The actual grid codes require the wind turbine to remain connected to the grid during fault condition and low voltage $[7,8,5]$. There are 
different LVRT solutions among them are: Active crowbar, Converter control of current, Dc converter with energy storage [5, 7].

Generally wind turbines are equipped with the crowbar, which short-circuits the rotor during fault, and disables the rotor side converter, thus the turbine is not controlled. In the wind farm with the big wind turbines the lost of one or more turbines could lead to the system unbalance even the system collapse. The combination of the fault current limiter (FCL) with braking resistor is proposed in this work. The FCL is used to limit the rotor fault current. To reduce the wind turbine active power, and maintain the DC link voltage at its rated value, the converter is equipped with a braking resistor (BR), which dissipates the wind turbines power. The user wind turbine component and the controls are implemented in PSCAD/EMTDC.

The $3 \mathrm{MW}$ wind turbine generator using doubly fed induction generator is connected to the network to verify the control and protection strategies.

\section{Wind turbine model}

The mechanical power extracted from the wind by turbine with blade radius $\mathrm{R}$ can be expressed as (1) $[9,10]$ :

$$
P_{w t}=\frac{1}{2} \operatorname{tr} R^{2} V_{w}^{3} C_{p} \hat{m}, b
$$

Where $C_{P}\left(\lambda_{v} \beta\right)$ is the wind turbine power efficiency, $v w$ is the wind speed and $\rho$ the air density.

The tip speed ratio is given by (2)

$m=\frac{R X_{L}}{V_{w}}$

Where $\Omega_{L}$ is the rotor speed.

The wind turbine torque is defined as (3)

$$
T_{w t}=\frac{P_{w} t}{X_{L}}=\frac{1}{2} \operatorname{tr} R^{2} \underset{V_{w}^{2}}{C_{p} \hat{m}, b} \mathbf{l}
$$

Wind turbine power coefficient can be expressed by the formula (4) [11]:

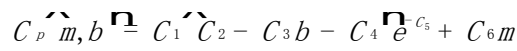

$$
\begin{aligned}
& C_{1}=0.5176 \\
& C_{2}=\frac{116}{m^{i}} \\
& C_{3}=0.4 \\
& C_{4}=5.0 \\
& C_{5}=\frac{21}{m_{i}} \\
& C_{6}=0.0068 \\
& \frac{1}{m i}=\frac{1}{m+0.08 b}-\frac{0.035}{b^{3}+1}
\end{aligned}
$$

Setting the rated values are as base value, per unit calculation gives the following expressions.

The wind power can be expressed as (5):

$P_{W t p u}=\frac{P_{W t}}{P_{N}}=k C_{p \_p u \stackrel{3}{V_{W} p u}}$

Where $\mathrm{kp}$ is the per unit power at rated wind speed.

The per unit power coefficient is given by (6)

$C_{p \_p u}=\frac{C_{p} \bar{m}, b^{\mathbf{I}}}{C_{p \_\mathrm{max}}}$

The per unit wind speed is defined as (7)

$V_{W \_p u}=\frac{V_{W}}{V_{N}}$

Where $v_{w_{-} g}$ is the rated wind speed.

The per unit wind turbine torque is defined as (8)

$$
T_{W \_p u}=\frac{P_{W t p u}}{X_{L \_p u}}
$$

The per unit turbine mechanical speed is (9)

$\mathrm{X}_{L \_p u}=\frac{\mathrm{X}_{L}}{\mathrm{X} L_{-} r}$

$\Omega_{L_{-} y}$ is the rated mechanical speed of the low speed shaft.

The wind turbine dynamic (in pu) is represented in the figure 1. 


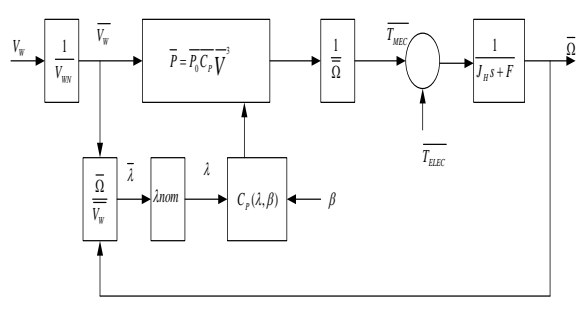

Fig. 1: Wind turbine model

The induction machine equations in $\mathrm{dq}$ coordinates (in per unit) are used. From the dynamic equations of the asynchronous machine, the generator and converter together is modeled like a voltage source behind impedance. In fact, the rotor and the converter acts through the rotor flux like the exciter and control the stator voltage.

The rotor currents $\bar{t}_{d y}, \bar{i}_{q Y}$ are derived from rotor flux equation and substituted in stator voltage equation. After manipulations we got the dq components of the voltage behind a transient reactance defined as (10) and (11)[12]

$$
\begin{aligned}
& \overline{e_{d}}=-\frac{\overline{s_{L}}}{\overline{L_{R R}}} \overline{m_{q r}} \\
& \overline{e_{d}}=\frac{\widetilde{{ }_{S} L_{M}}}{\overline{L_{R R}}} \overline{m_{d r}}
\end{aligned}
$$

The stator flux vector can be expressed as (12)[13]

$$
\begin{aligned}
& \overline{m d s}=\#^{\prime \hat{V d s}}-\overline{R s} \overline{\dot{i}_{d s}} \boldsymbol{\mathbf { h } _ { i }} \\
& \overline{m_{q s}}=\#^{\prime \underline{V q s}}-\overline{R s} \overline{i_{q s}} \mathbf{\mathbf { h } _ { i }}
\end{aligned}
$$

The rotor flux equations in $\mathrm{dq}$ frame can be written as shown in formula (13)

$\overline{m d r}=\overline{\frac{L R R}{\overline{L M}}} \frac{\hat{m} d s}{V}+\overline{L s} \overline{\dot{I}_{d s}} \mathbf{t}$ $\overline{m_{q r}}=\overline{\frac{L_{R R}}{\overline{L_{M}}}} \hat{\overline{m_{q S}}}+\overline{V \bar{L}} \overline{\dot{I}_{q s}} \mathbf{F}$

The rotor flux and the internal voltage magnitude and angle determination diagram are shown in figure 2.

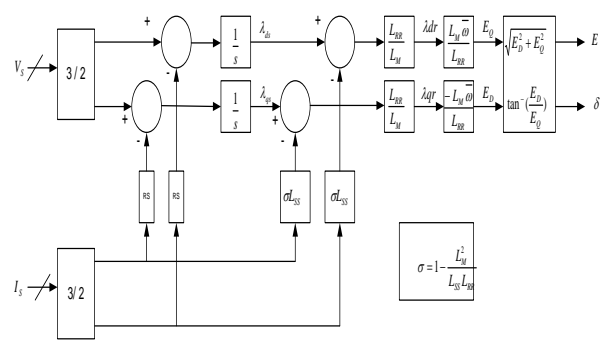

Fig. 2: Internal voltage magnitude and angle

\section{Wind turbine control}

The mechanical control of the wind turbine is presented in figure 3 . The available power from turbine aerodynamic is compared with the reference power, the difference is passed through a PI regulator to provide the turbine blade angle deviation .The power reference is the sum of the power of reference $\mathrm{P}_{\text {ref1 }}$ provided by the maximum power tracking (MPT) and the power reference $\mathrm{P}_{\text {ref2 }}$ obtained from the rotor speed control. Depending on the wind speed and the rotor speed, the wind turbine is forced to follow an optimum power curve.

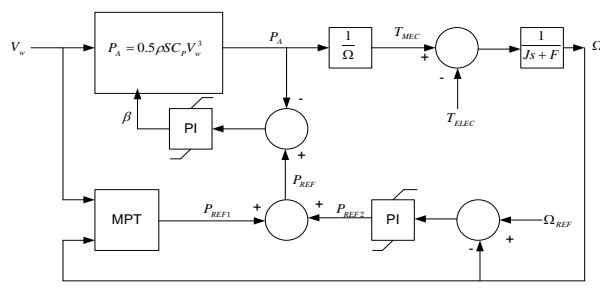

Fig. 3: Wind turbine control

The overall control of the wind turbine diagram, including the interface converter is depicted in figure 4 . 
The rotor side converter controls wind turbines terminal voltage, active power and the internal voltage magnitude and angle, while the grid side converter maintains the DC link voltage.

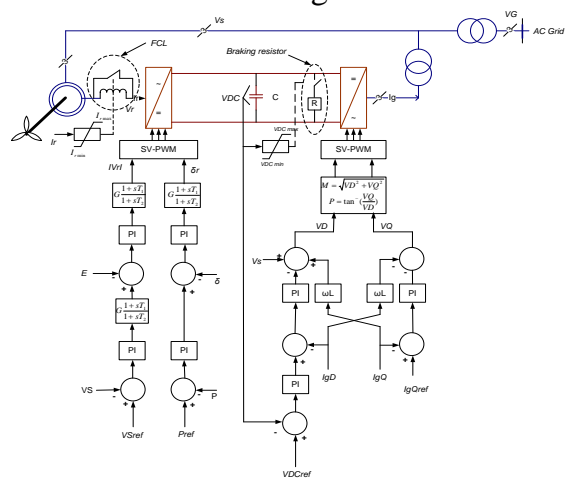

Fig. 4: Wind turbine overall control diagram

Generally, in wind turbines using DFIG, during the network fault the rotor side converter is short- circuited, thus the generator is no longer controlled. In the case of large-scale wind farm, the loss of the converter in the event of fault can lead to the instability or even the network collapse. In this work, we propose the wind turbine to be controlled by the converter during fault. During a fault, when the rotor current exceeds the threshold limit $(1.2 \mathrm{pu})$, the IGBTs are blocked, and then the current will flow into the DC link through the freewheeling diodes leading to the DC voltage over-voltage. To limit the rotor current during fault, we propose the fault current limiter (FCL). The FCL is an inductance connected in series with the rotor winding. In normal operation, FCL switch is turned ON to bypass the inductance. When the rotor current exceeds a certain threshold, the FCL switch is turned OFF to insert the inductance.

In order to limit the de link voltage during the fault a DC chopper called active crowbar is employed.

The chopper is activated to keep the DC voltage within the normal value by dissipating the excess power from the rotor.

\section{Simulation}

To investigate the behavior of wind farm during disturbances, a $100 \mathrm{~ms}$ Threephase fault to ground fault is applied at wind turbine terminal at the time $\mathrm{t}=29.5$, $10 \mathrm{~s}$ after a $100 \mathrm{~ms}$ single phase to ground fault is applied at the same place. The simulation data are shown in the table 1 . The first simulation concern is the wind turbine connected into the grid without the fCL and the active crowbar; the results are depicted in the figures 5 thru 9 below.

The grid parameters: RMS voltage, Three- phase AC voltage, active and the reactive power are plotted in the figure 6 .

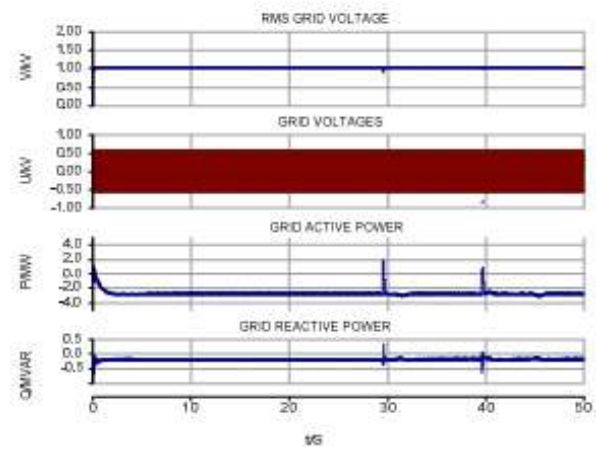

Fig. 5: RMS voltage, three-phase AC volt age, active and the reactive power

In the figure 6 are plotted wind turbine parameters.

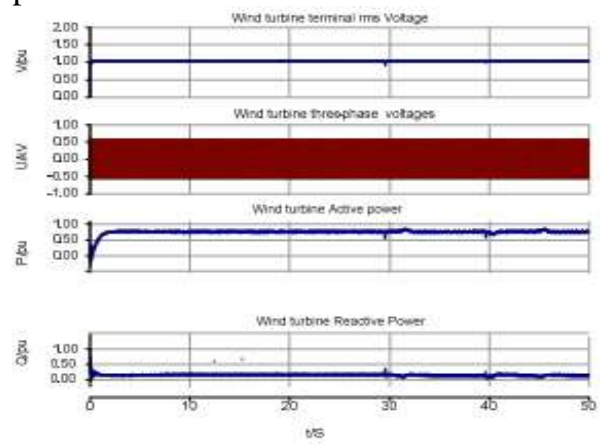

Fig. 6: Wind turbine terminal RMS voltage, three phase AC voltage, the active and reactive powers. 
Figure 7 shows the rotor and wind speed.
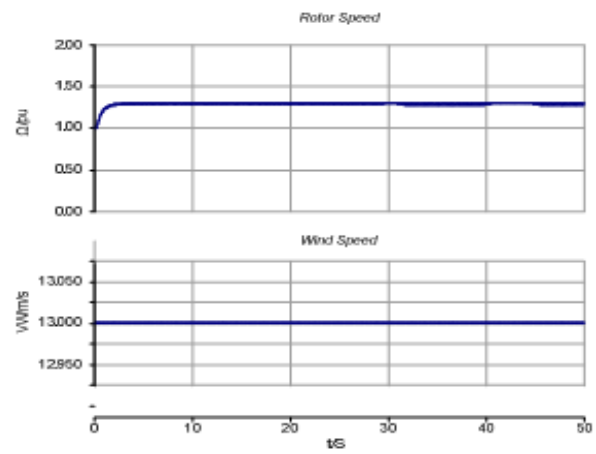

Fig. 7: Rotor and Wind Speed

Figure 8 illustrates how the rotor current rises during fault.

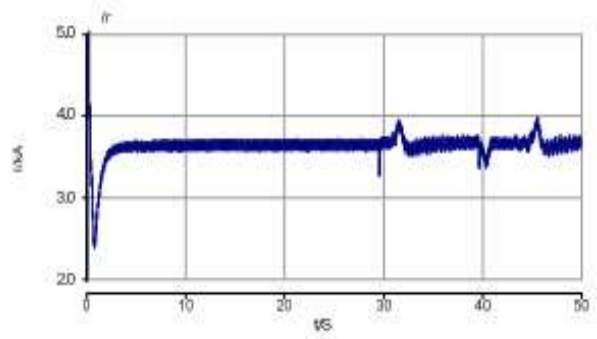

Fig. 8: Rotor Current

In figure 9 is plotted the DC link voltage during faults.

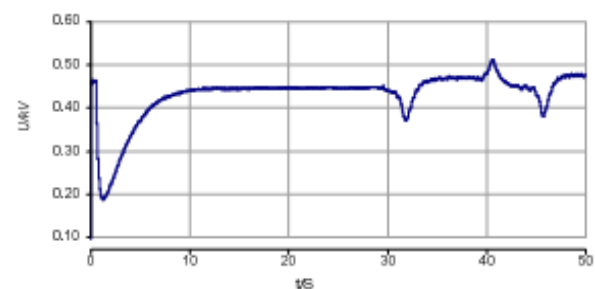

Fig. 9: DC Link Voltage

In the second simulation the wind turbine is connected into the grid with the fCL and the active crowbar; the simulation results are illustrated in the figures 10 thru 14.

Grid parameters are shown in the figure 10 .

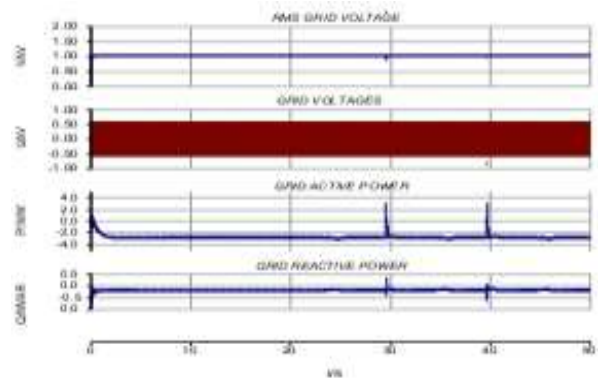

Fig. 10: RMS voltage, three phases AC voltage, active and the reactive power

Wind turbine parameters are depicted in the figure 11 .

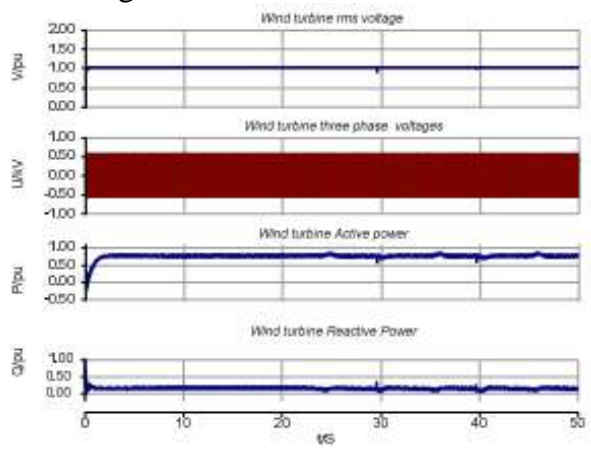

Fig. 11: Wind turbine terminal RMS voltage, three phase AC voltage, active and reactive power

Figure 12 depicts the rotor and wind speed variations.
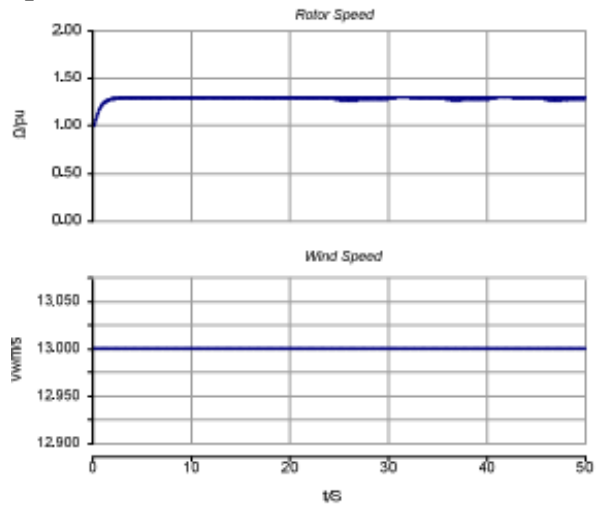

Fig. 12: Rotor and Wind Speed

In the figure 13 we can see that the fault current don't rise during faults. 


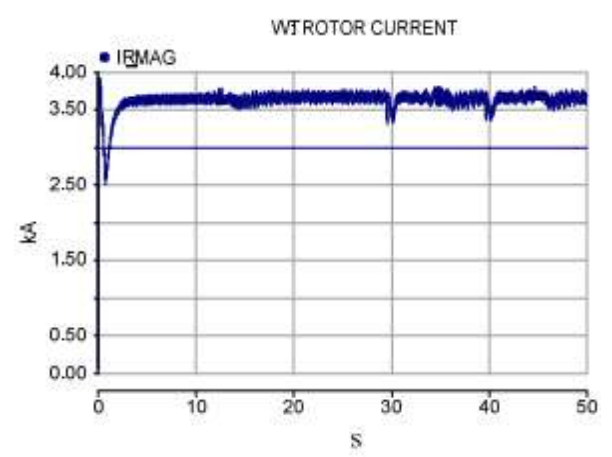

Fig. 13: Rotor Current

The figure 14 shows how the DC link voltage is maintained within it normal value.

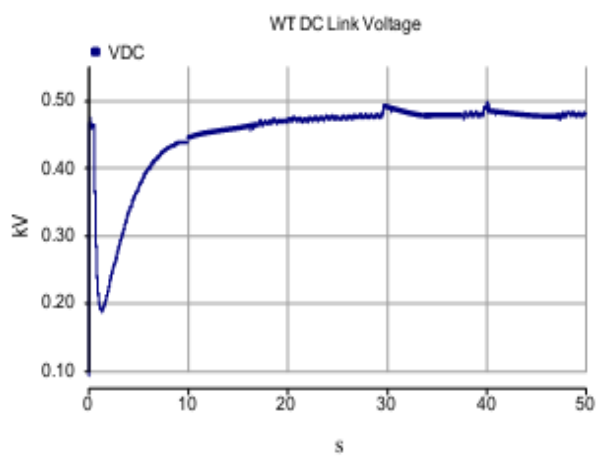

Fig 14: DC Link Voltage

\section{Conclusion}

As seen, the rotor current rises and then the DC link voltage increase during both three phase fault and single phase fault. When the FCL is connected the fault current is reduced, so the DC link voltage rise is limited by the braking resistor ensuring the protection of the rotor converter. Thus during the fault the converter remains connected and controls the turbine ensuring the uninterruptible operation of the converter. Such a combination of FCL and braking resistor can be used to protect the DFIG wind turbine during symmetrical and asymmetrical faults.

\section{Appendix}

Table 1Wind turbine and DFIG generator data

\begin{tabular}{|ll|}
\hline \multicolumn{2}{|c|}{ Wind turbine data } \\
\hline Power & $3.0 \mathrm{MW}$ \\
Mean wind speed & $12.0 \mathrm{~m} / \mathrm{s}$ \\
Rated TSR & 8.1 \\
Rated mechanical & $1.2 \mathrm{pu}$ \\
speed & \\
Power gain kp & $0.73 \mathrm{pu}$ \\
\hline \multicolumn{2}{|c|}{ DFIG Generator data } \\
\hline Voltage/frequency & $0.69 \mathrm{kV} / 60 \mathrm{~Hz}$ \\
Stator resistance & $0.003973 \mathrm{pu}$ \\
Rotor resistance & $0.206719 \mathrm{pu}$ \\
Stator leakage in- & $0.069513 \mathrm{pu}$ \\
ductance & \\
Rotor leakage in- & $0.069513 \mathrm{pu}$ \\
ductance & \\
Magnetizing induct- & $1.50432 \mathrm{pu}$ \\
ance & \\
\hline
\end{tabular}

\section{Reference}

[1] Vladislav akhmatov,'Variable-Speed Wind Turbines with Doubly-Fed Induction Generators Part III: Model with the Back-to-back Converters", wind ENGINEERING VOLUME 27, No.2, 2003 pp 79-91

[2] Aranxa Tapia, Gerardo Tapia, J.Xabier Ostalaza, and Jose Ramon Saenz, "Modeling and Control of a Wind Turbine Driven Doubly Fed Induction Generator",Energy Conversion, IEEE Transactions on , vol.18, no.2, pp. 194- 204, June 2003

[3] R.Pena, J.C.Clare, G.M.Asher, "Doubly fed induction generator using back-to-back PWM converters and its application to variable-speed wind-energy generation", IEE Proc.Electr.Power Appl, Vol. 14.3, No 3. May 1996, pp.231-241.

[4] Fernando D. Bianchi, et al, "Wind Turbine Control Systems: Principles, Modelling and Gain Scheduling Design”, Springer July 2006. 
[5] KONE Ibrahima, Chengyong Zhao, "Modeling of Wind Energy Conversion System Using Doubly Fed Induction Generator Equipped Batteries Energy Storage System", Electric Utility Deregulation and Restructuring and Power Technologies (DRPT), 2011 4th International Conference on, pp.1780-1787.

[6] O. Anaya-Lara, F. M. Hughes, N. Jenkins, and G. Strbac, "Rotor flux magnitude and angle control strategy for doubly fed induction generators", Wind Energy, Vol. 9. No. 5, pp. 479-495, June 2006.

[7] Zhenhua Jiang, Xunwei Yu,"Modeling and control of an integrated wind power Generation and Energy Storage system" Power \& Energy Society General Meeting, 2009. PES '09. IEEE, pp.1-8.

[8] C.Wessels.F.W.Fuchs,"High Voltage Ride Through with FACTS for
DFIG Based Wind Turbines", EPÉE 2009-Barcelona,pp P.1-P.10.

[9] Manfred Stiebler,"Wind Energy systems for Electric Power Generation" ,Springer 2008

[10] Iulian Munteanu, Antoneta Iuliana Bratcu, Nicolaos-Antonio Cutululis, Emil ceanga,"Optimal control of wind Energy systems", Springer 2008.

[11] Siegfried Heier, "Grid Integration of Wind Energy Conversion Systems," John Wiley \& Sons Ltd, 1998, ISBN 0-471-97143-X

[12] Olimpo anaya-lars, nick lenkins, janaka ekanayake, phill cartwright, mike hughes "wind energy generation modelling and control", wiley 2009.

[13] Bin wu, "high-power converters and ac drives", wiley ieee press 2006. 